\title{
Research on the Semi-transverse Ventilation and Smoke Exhaust Strategy in Sloping Tunnels
}

\author{
Yonghai Qiu * \\ School of Electric Power South China University of \\ Technology \\ Guangzhou, China \\ qiu.yonghai@qq.com \\ * Corresponding Author
}

\author{
Bo Lou \\ School of Electric Power South China University of \\ Technology \\ Guangzhou, China \\ loubo@scut.edu.cn
}

\begin{abstract}
In this paper, the influence of slope on the spreading characteristics of fire smoke in the semitransverse ventilated tunnels was studied by using the FDS simulation. Through simulation experiments, the reasonable smoke exhaust strategies for preventing fire smoke from spreading in the sloping tunnel were obtained. Simulation results showed that: under 30MW fire power, the two-way balanced smoke exhaust strategy had good effect for the semi-transverse ventilated horizontal tunnel. However, in the sloping tunnel, due to the high stack effect, more smoke flowed to the upgrade direction. When the slope angle was greater than $1.5 \%$, the smoke in the downgrade direction was controlled within the smoke vent opening range due to the effect of fire wind pressure. At this time, in order to effectively exhaust the smoke and reduce the energy consumption of the smoke exhaust fan, the unilateral smoke exhaust strategy in the upgrade direction was adopted. When the tunnel slope was less than $2 \%$, appropriately increasing the smoke exhaust amount could strengthen the smoke exhaust effect and prevent the smoke from spreading to the exit of the tunnel. When the slope was greater than $3 \%$, due to the high stack effect, the smoke in the tunnel spread rapidly to the exit. Then adding the vertical ventilation in the upgrade direction and preventing the smoke from returning could better limit the smoke spreading scope.
\end{abstract}

Keywords-Slope: Smoke Exhaust Strategy; Tunnel Fire; Smoke Spread; Semi-transerse Ventilation

\section{INTRODUCTION}

Although the high-temperature smoke can damage the tunnel structure in the tunnel fire, the data shows that the high-speed spreading toxic smoke produced in the fire such as carbon monoxide is the greatest threat to the personnel safety in tunnel [1]. Therefore, when the fire breaks out, how to effectively use the mechanical smoke exhaust system to prevent the fire s moke from spreading is very important. Since the semi-transverse ventilation system can exhaust the smoke effectively in a fire and control it in a short area in the tunnel, it is suitable for the long tunnel and has gradually become a development trend. In a horizontal tunnel, the smoke vents are symmetrically distributed on both sides of the fire in the traditional mechanical smoke exhaust layout. Opening the smoke exhaust fans on both ends at the same time can prevent the smoke from spreading well and exhaust the smoke effectively. Many scholars have studied the influence of the shape, spacing and amount of the smoke vent on the fire smoke exhaust efficiency in the horizontal tunnel under the two-way balanced smoke exhaust strategy [2-5]. However, tunnels are generally sloped. According to Code for Design of Road Tunnel (JTGD 70-2004)) in China, the slope of the tunnel should be more than $0.3 \%$ and less than $3 \%$. Sometimes, the slope is greater in the special terrain, which leads to the different smoke spreading characteristics in fire from the horizontal tunnel. Under the influence of the stake effect caused by tunnel slope, the smoke on the upgrade spreads very strongly, which increases the difficulties for smoke control and ventilation and smoke exhaust design. In recent years, scholars' research on the fire protection work in the sloping tunnels mainly focuses on the influence of the slope on the smoke temperature distribution in the tunnel [6-8] and the critical ventilation speed for inhibiting the smoke to return under the longitudinal ventilation [9-12]. There has been rare report on the smoke spread in the semi-transverse ventilation system. Related studies [13,14] show that the smoke spreading characteristic in the sloping tunnel is different from that in the horizontal tunnel. Under different tunnel slopes, it needs to adopt different smoke exhaust strategies to effectively prevent the smoke from spreading in the tunnel and facilitate the personnel evacuation and fire rescue work. Ballesteros-Tajadura [13] studied the smoke spreading characteristics at the slope section of Inner Belt tunnel (slope=2\%) under the semi-transverse ventilation system with the FLUENT nu merical simu lation and the results showed that the smoke exhaust amount of the fan under the engineering design cannot exhaust the smoke effectively and some smoke spreads to the downstream of the tunnel under the sloping effect, and also put forward that the smoke vent should be put in the upgrade direction of fire and the standard smoke exhaus $t$ layout (smoke vents are distributed on both ends of fire symmetrically) will reduce the mechanical smoke exhaust efficiency sharply. However, the smoke spreading characteristics under the tunnel slope of $2 \%$ were just studied. Lin [14] researched the influence of the slope on the smoke control in the tunnel under the semi-transverse ventilation system with FDS simulation and the results showed that the smoke exhaust rate increased by $5 \%$ to 
$20 \%$ when the slope varied from $1 \%$ to $5 \%$. The tunnel physical model simplifies the semi-transverse ventilation and smoke exhaust gallery layout and puts the smoke exhaust fan directly at the smoke vent on the roof of the tunnel, but ignores the influence of putting the fans on both sides of the exhaust gallery in reality on the smoke exhaust effect. In order to reflect the influence of the smoke exhaust strategy of the semi-transverse ventilated sloping tunnel with the smoke exhaust gallery on the fire smoke spreading characteristics, the fire smoke spreading distance in the semi-transverse ventilated sloping tunnel is analyzed with FDS large eddy simulation method. And, the influence of the slope on the smoke exhaust effect of the semi-transverse ventilation system is also explored, so as to obtain the reasonable smoke exhaust strategy in sloping tunnels.

\section{NUMERICAL CALCUlation MODEL}

In the study of the fire smoke flow regularity, due to the limitations of the experimental research, the numerical simulation technology has been widely used. Over the past twenty years, the CFD simulation of fire has been improved continuously with the deepening of the turbulence theory research and the improvement of the computer performance. The CFD simulation of fire is also known as the field simulation which can be divided into DNS, RNAS and LES. In this paper, the LES model in FDS is adopted for the numerical research of smoke flow when the fire breaks out in the sloping tunnel. FDS is a developed by the US NIST especially for the fire simulation research. It is widely used by scholars in the fire research. $\mathrm{Hu}$ [15] studied the highest temperature distribution on the roof of the tunnel where the fire broke out with FDS simulation, and the simulation results agreed with the experimental results. Hu [16] predicted the critical ventilation speed when the fire broke out at different cross sections of the tunnel by combining theoretical analysis and FDS simulation together. Sung [17] studied the influence of the cross section proportion of the tunnel on the smoke spreading characteristics in it with FDS 3.0 simulation and analyzed the smoke temperature distribution on the roof. After comparison with the experimental results, the error is less than $10{ }^{\circ} \mathrm{C}$. The research of many scholars shows that it is feasible and effective to study the fire smoke spreading characteristics and temperature distribution in the tunnel with FDS.

\section{A. Verification of the Reliability of the Numerical Calculation Model}

In this paper, based on the similarity theory and combined with an actual tunnel engineering, a small-size wind tunnel experimental device of tunnel fire which could simulate multiple conditions and whose slope could be adjusted was developed, as shown in Figure 1. The whole experimental system of the model contained axial flow fan, model tunnel, slope adjustment device, car movement device, temperature measurement system, wind speed measurement system and smoke exhaust system. The model tunnel was simulated by the steel structure pipes with the size of $10 \mathrm{~m}$ (length) $\times 0.9 \mathrm{~m}$ (width) $\times 0.5 \mathrm{~m}$ (height). Its horizontal angle could be adjusted between 70 and +70 . The experiment verified the vertical temperature distribution on the roof at $3 \mathrm{~m}$ from the tunnel entrance where the stationary fire with the tunnel slopes of $3 \%$ and $6 \%$ was located. The comparis on between the simulation results and the experimental results was shown in Figure 2. According to the figure, the model used by FDS in the paper could truly reflect the smoke spreading characteristics when the fire broke out in the sloping tunnel.



Figure 1. Systematic Diagram of the Tunnel Testing Table

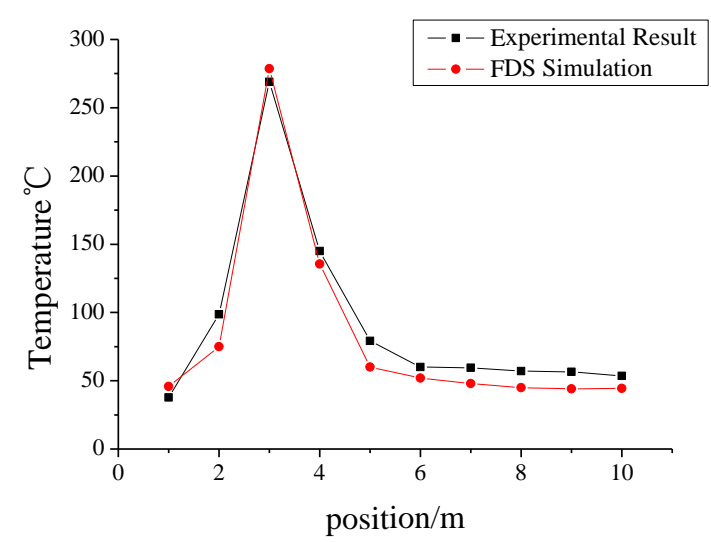

(a) Slope $=3 \%$

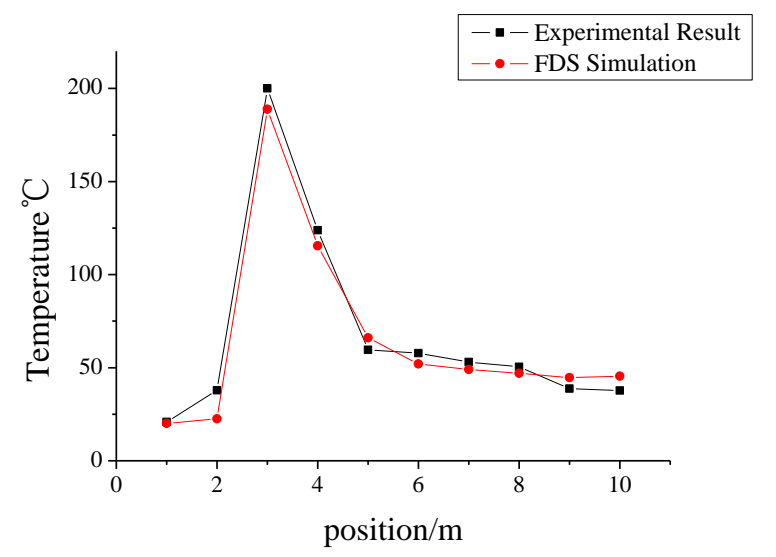

(b) Slope $=6 \%$

Figure 2. Comparison between the Simulation Results and the Experimental Results

\section{B. Theoretical Calculation of the Smoke Exhaust Volume}

The smoke exhaust volume parameter of the fan in the tunnel should be greater than the generated smoke volu me, so as to emit smoke to the tunnel rather than accumulating in it. According to Technical specification for building smoke control (DJG 08-88-2006) [18], the theoretical mas s flux of the axisymmetric plume s moke generated by the fire in the tunnel can be obtained by the following formula.

$$
\begin{aligned}
& z \leq z_{l}, M_{p}=0.032 Q_{c}^{3 / 5} z \\
& z>z_{l}, M_{p}=0.071 Q_{c}^{1 / 3} z^{5 / 3}+0.0018 Q_{c}
\end{aligned}
$$


where $z$ is the height from the fuel surface to the bottom of the fire $(\mathrm{m}) ; z_{l}$ is the limited height of the flame $z_{l}=0.166 Q_{c}^{2 / 5}(\mathrm{~m}) ; M_{p}$ is the plume mass flux $(\mathrm{kg} / \mathrm{s})$ and $Q_{c}$ is the convective heat release rate of fire $(\mathrm{kW})$, $Q_{c} \approx 0.7 Q$.

The volume flux can be obtained according to the plume mass flux of fire:

$$
\begin{aligned}
& V_{p}=\frac{M_{p} T}{\rho_{0} T_{0}} \\
& T=T_{0}+\frac{Q_{c}}{M_{p} c_{p}}
\end{aligned}
$$

Where, $V_{p}$ is the volume flow of the generated smoke $(\mathrm{m} 3 / \mathrm{s}) ; T$ is the average temperature of a plume $(\mathrm{K}) ; \rho_{0}$ is the density of the ambient air $(\mathrm{kg} / \mathrm{m} 3) ; T_{0}$ is the ambient temperature $(\mathrm{K})$. The minimu $\mathrm{m}$ fire exhaust volumes under different fire powers can be calculated according to the formula above, as shown in Table 1.

TABLE I. PLUME FLOW IN DIFFERENT HEAT RELEASE RATE

\begin{tabular}{ccc}
\hline $\begin{array}{c}\text { Heat release } \\
\text { rate }(\mathrm{KW})\end{array}$ & $\begin{array}{c}\text { Mass } \\
\text { flow }(\mathrm{kg} / \mathrm{s})\end{array}$ & $\begin{array}{c}\text { Volume } \\
\text { flow }\left(\mathrm{m}^{3} / \mathrm{s}\right)\end{array}$ \\
\hline 10 & 38.1 & 51.2 \\
20 & 57.1 & 87.5 \\
30 & 72.8 & 119.1 \\
\hline
\end{tabular}

In the simulative research, the smoke exhaust efficiency was considered. The maximum s moke exhaust volume of a single fan was set to $140 \mathrm{~m}^{3} / \mathrm{s}$.

\section{Grid Independence Verification}

In the numerical simulation research, the grid size is a very important parameter. In the FDS LES model, the grid size simulating the calculation area must meet the SGS, in order to accurately calculate the viscosity stress model in the flow field. Thus, the grid size near the fire source is generally determined by the characteristic length of the fire $D^{*}$.

$$
D^{*}=\left(\frac{Q}{\rho_{\infty} \mathrm{c}_{p} T_{\infty} g^{1 / 2}}\right)^{2 / 5}
$$

Where, $D^{*}$ is the characteristic length of the fire; $\mathrm{m}, Q$ is the fire power $(\mathrm{kW}) ; \rho_{\infty}$ is the ambient density $\left(\mathrm{kg} / \mathrm{m}^{3}\right)$; $c_{p}$ is the specific heat at constant pressure $(\mathrm{kJ} /(\mathrm{kg} \cdot \mathrm{K}))$; $T_{\infty}$ is the ambient temperature; $\mathrm{K}, g$ is the acceleration of gravity $\left(\mathrm{m} / \mathrm{s}^{2}\right)$.

McGrattan[19] found from the research that when the grid size was $0.1 D^{*}$, the FDS LES results agreed with the experimental fitting curve. In this paper, the fire power was simulated to $30 \mathrm{MW}$. The characteristic length of the fire was $4 \mathrm{~m}$ after calculation. Therefore, the grid size $\left(0.1 D^{*}\right.$, or $\left.0.4 \mathrm{~m}\right)$ was reasonable. Considering the sizes of the smoke vent and the smoke exhaust fan in simulation, the grid size was determined to $0.32 \mathrm{~m} \times 0.32 \mathrm{~m} \times 0.32 \mathrm{~m}$.

\section{FDS Numerical Physical Model}

In this paper, FDS was used to construct the full-scale model of a tunnel with the dimension of $400 \mathrm{~m} \times 10.2 \mathrm{~m} \times 7.68 \mathrm{~m}$, as shown in Fig. 3. The flue sheet was set at the height of $5.76 \mathrm{~m}$, being $0.32 \mathrm{~m}$ thick. The fire was located in the middle of the tunnel. The fuel was propylene brought by FDS with the power of $30 \mathrm{mw} .6$ groups of smoke vents with the size of $3 \mathrm{~m} \times 3 \mathrm{~m}$ were located in the middle of the flue sheet and symmetrically distributed on both ends of the fire wit the spacing of $40 \mathrm{~m}$. The smoke exhaust fans were distributed at the exits on both sides of the smoke exhaust gallery. The simulation time was $6 \mathrm{~min}$. The simulation condition of the smoke exhaust strategy was shown in Table 2.

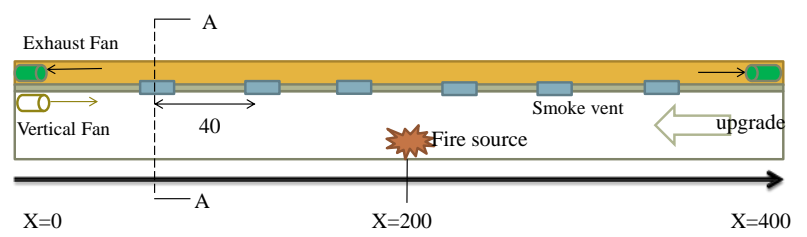

(a) Longitudinal Distribution of the Tunnel

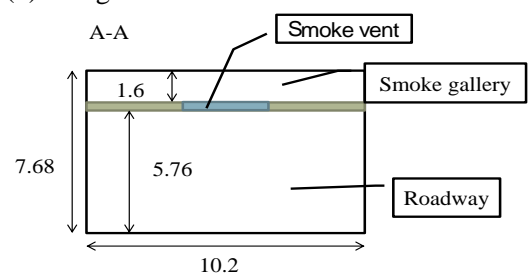

(b) A-A Cross-section Diagram

\begin{tabular}{|c|c|c|c|c|}
\hline \multirow[t]{2}{*}{ case } & \multirow[t]{2}{*}{ slope\% } & \multicolumn{2}{|c|}{$\begin{array}{c}\text { Fan exhaust } \\
\text { volume }\left(\mathrm{m}^{3} / \mathrm{s}\right)\end{array}$} & \multirow{2}{*}{$\begin{array}{c}\text { Vertical } \\
\text { ventilation }(\mathrm{m} / \mathrm{s})\end{array}$} \\
\hline & & upgrade & downgrade & \\
\hline 1 & 0 & 60 & 60 & 0 \\
\hline 2 & 1 & 60 & 60 & 0 \\
\hline 3 & 1 & 100 & 40 & 0 \\
\hline 4 & 1.5 & 120 & 0 & 0 \\
\hline 5 & 2 & 120 & 0 & 0 \\
\hline 6 & 2 & 140 & 0 & 0 \\
\hline 7 & 3 & 120 & 0 & 0 \\
\hline 8 & 3 & 140 & 0 & 0 \\
\hline 9 & 3 & 120 & 0 & 1.5 \\
\hline 10 & 5 & 120 & 0 & 0 \\
\hline 11 & 5 & 140 & 0 & 0 \\
\hline 12 & 5 & 120 & 0 & 1.5 \\
\hline
\end{tabular}

Figure 3. Schematic Diagram of the Tunnel Model

TABLE II. SIMULATION CONDITION

III. SimUlatiOn RESUlTS AND ANALYSIS

Figure 4 was the smoke spreading state diagram of the tunnels with the slopes of $0 \%$ and $1 \%$ under the two-way smoke exhaust strategy (case 1 and 2). It could be seen from Figure 4 (a) that when the slope was $0 \%$, the fire smoke was symmetrically distributed with the fire source as the center. At this time, the two-way smoke exhaust strategy could control the smoke within a certain range. However, when the slope increased to $1 \%$, as shown in Figure 4(b), little smoke returned in the upgrade direction of the tunnel and more deviated towards the upgrade direction under the action of the buoyancy effect, making the upgrade direction of the tunnel full of s moke. The smoke spread to the exit of the upgrade. Due to the reduction of the smoke spreading distance in the downgrade direction, the smoke exhaust ability of the 
smoke vent failed to be fully used. Thus, at this time, the best strategy should be to strengthen the smoke exhaust in the upgrade direction and reduce the smoke exhaust in the downgrade direction. Figure 5 was

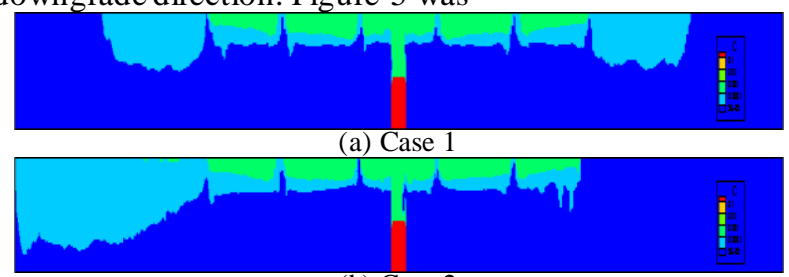

(b) Case 2

Figure 4. Cases 1,2, the smoke spreading state diagram under the twoway smoke exhaust strategy

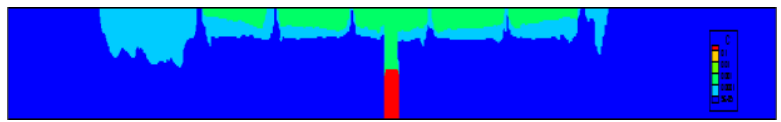

Figure 5. Case 3, the smoke spreading state diagram

the smoke spreading status diagram in the tunnel under case 3. At this time, the smoke exhaust volume in the upgrade direction increased to $100 \mathrm{~m}^{3} / \mathrm{s}$ while that in the downgrade direction reduced to $40 \mathrm{~m}^{3} / \mathrm{s}$. It could be seen that the smoke spread was suppressed near the opening range of the smoke vent, making its smoke exhaust ability be put to great use.

From the above, with the increase of the tunnel slope, the stack effect was strengthened, so the smoke exhaust ability in the upgrade direction should continue to be strengthened and that in the downgrade direction could be reduced. When the slope increased to a certain extent, the unilateral s moke exhaust strategy in the upgrade direction could be used. Figure 6 was the smoke spreading status in the tunnel under the unilateral smoke exhaust strategy when the slope was $1.5 \%$ and the smoke exhaust volume in the upgrade direction was $120 \mathrm{~m}^{3} / \mathrm{s}$. According to the figure, the fire smoke could be well inhibited in a certain range of the tunnel and the smoke exhaust ability was fully used. Thus, when the slope was greater than $1.5 \%$, the unilateral smoke exhaust in the upgrade direction could be adopted to emit the smoke in the tunnel, which could not only effectively inhibit the smoke spread, but also reduce the total energy consumption of the fan.

Figure 7 showed the smoke spreading diagrams in the tunnel under the unilateral smoke exhaust in the upgrade direction when the slope was $2 \%$ and the smoke exhaust volumes were $120 \mathrm{~m}^{3} / \mathrm{s}$ and $140 \mathrm{~m}^{3} / \mathrm{s}$, respectively. According to the figure, when the smoke exhaust volume was $120 \mathrm{~m}^{3} / \mathrm{s}$, due to the enhancement of the stake effect, although a large amount of smoke was emitted, there was still some spreading to the exit of the tunnel, which was not conductive to the personnel escape in the upgrade direction. In order to effectively emit the smoke to the tunnel and inhibit the smoke return, the best strategy should be to strengthen the smoke exhaust or increase the smoke exhaust volume in the upgrade direction. When the smoke exhaust volume increased to $140 \mathrm{~m}^{3} / \mathrm{s}$, the smoke spread was well inhibited, as shown in Figure 7 (b).

Figure 8 was the smoke spreading diagrams in the tunnel under the unilateral smoke exhaust in the upgrade direction when the slope was $3 \%$ and the smoke exhaust volumes were $120 \mathrm{~m}^{3} / \mathrm{s}$ and $140 \mathrm{~m}^{3} / \mathrm{s}$, respectively. It could be known from comparing two diagrams that they both could not inhibit the smoke to spread. The fire smoke spread to the exit of the tunnelunder two conditions. It

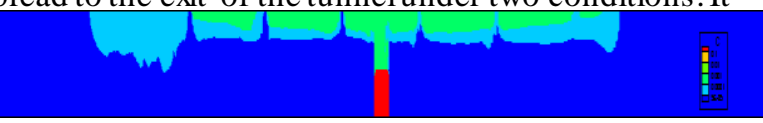

Figure 6. Case 4, the smoke spreading status under the unilateral smoke exhaust when the slope was $1.5 \%$

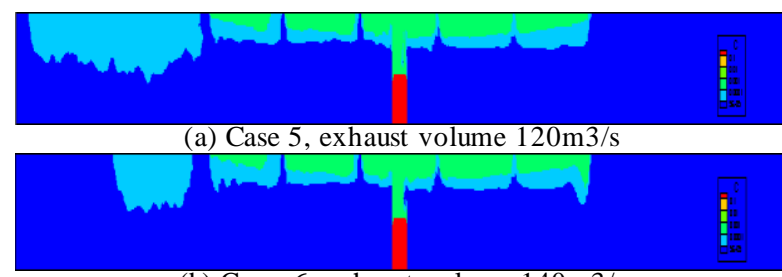

(b) Cases 6, exhaust volume $140 \mathrm{~m} 3 / \mathrm{s}$

Figure 7. Case 5, 6, the smoke spreading diagrams under the unilateral smoke exhaust when the slope was $2 \%$

indicated that increasing the smoke exhaust amount could not control the smoke spread to the exit of the tunnel under this slope. This was because when the slope increased to a certain value, leading to the smoke spreading speed to the upgrade direction of the tunnel to increase. The smoke spread at a high speed, so a large amount of smoke spread escaped from the smoke vents but spread to the exit of the tunnel. At this time, the semitransverse ventilation was unable to inhibit the smoke to return towards the upgrade direction. Thus, the blower in the upgrade direction was opened (see Figure 1) to increase the longitudinal ventilation. Figure 9 showed the working condition 9 under the strategy of increasing the longitudinal ventilation in the upgrade direction when the slope was $3 \%$, the smoke exhaust volume was $120 \mathrm{~m}^{3} / \mathrm{s}$, and the wind speed under ventilation was $1.5 \mathrm{~m} / \mathrm{s}$. According to the figure, under this smoke exhaust strategy, the fire smoke was well inhibited and the smoke return distance was controlled near the opening range of the smoke vent.

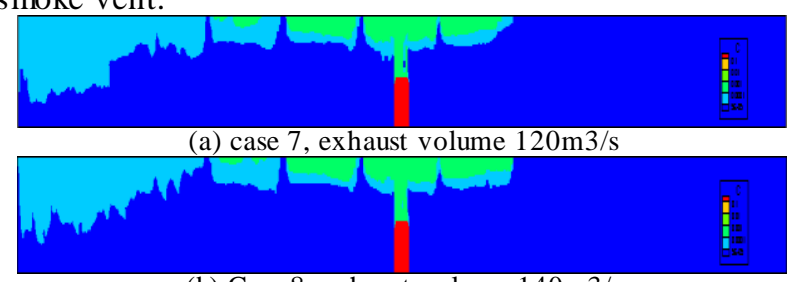

(b) Case 8 , exhaust volume $140 \mathrm{~m} 3 / \mathrm{s}$

Figure 8. Case 7, 8, the smoke spreading diagrams under the unilateral smoke exhaust when the slope was $3 \%$

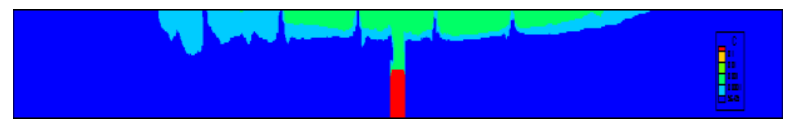

Figure 9. Case9, the smoke spreading diagrams under vertical ventilation when the slope was $3 \%$

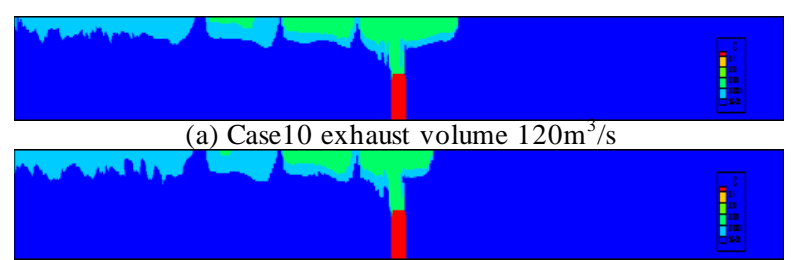

(b) Case 11 exhaust volume $140 \mathrm{~m} 3 / \mathrm{s}$

Figure 10. case 10,11, the smoke spreading diagrams under the unilateral smoke exhaust when the slope was $5 \%$ 


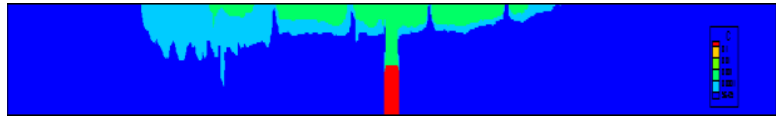

Figure 11. case12, the smoke spreading diagrams under vertical ventilation when the slope was $5 \%$

Figure 10 was the smoke exhaust diagrams under the unilateral s moke exhaust when the slope was $5 \%$ and the smoke exhaust volumes were $120 \mathrm{~m}^{3} / \mathrm{s}$ and $140 \mathrm{~m}^{3} / \mathrm{s}$, respectively. Similar to the condition when the slope was $3 \%$, it could not inhibit the smoke to spread to the exit of the tunnel, either. Thus, the best way was to increase the longitudinal ventilation, as shown in Figure 11. The wind speed under longitudinal ventilation was $1.5 \mathrm{~m} / \mathrm{s}$. It could be seen that the smoke was completely controlled within the opening range of the smoke vents and the smoke exhaust ability in the tunnel was fully used, which was conductive to the personnelescape in the tunnel.

\section{CONCLUSION}

Once the fire breaks out in tunnel, the generated toxic smoke is the most harmful to people in the tunnel. And, the spreading characteristics of the fire smoke in the sloping tunnel are more complicated. In this paper, the influence of the slope on the smoke exhaust effect of the semitransverse ventilated tunnel was studied based on the FDS simulation. The reasonable smoke exhaust strategies in the sloping tunnel were obtained through the simulated experiments.

1. In the sloping tunnel, the two-way balanced smoke exhaust strategy failed to inhibit the smoke spread, so it could not help the fire protection and rescue work in the tunnel.

2. When the tunnel slope was greater than $1.5 \%$, the unilateral s moke exhaust strategy could not only make full use of the smoke exhaust ability of the tunnel, but also reduce the energy consumption of the fan.

3. When the slope was less than $2 \%$, increasing the smoke exhaust volume could enhance the smoke exhaust effect and inhibit the spread of the smoke to the exit of the tunnel.

4. When the slope was greater than $3 \%$, due to the high stack effect, the smoke in the tunnel spread rapidly to the exit of the tunnel. At this time, increasing the increasing the smoke exhaust volume could not prevent the smoke from spreading to the exit of the tunnel. The best way was to increase the longitudinal ventilation in the upgrade direction and inhibit the smoke return

\section{ACKNOWLEDGMENT}

This work was funded by the Natural Science Foundation of Guangdong Province in China under Grant Number S2013010016748 and Guangdong Province Key Laboratory of Efficient and Clean Energy Utilization(2013A061401005), South China University of Technology

\section{REFERENCES}

[1] J. Jie, L. Kaiyuan, Z. Wei, H. Ran, Experimental investigation on influence of smoke vent ing velocity and vent height on mechanical smoke exhaust efficiency, J HAZARD MATER 177(1-3)(2010) 209-215

[2] Luan Jun, Influence of tunnel semi-transverse ventilation exhaust port setting on exhausting effect, Fire Science and Technology (07)(2013)727-730

[3] Liu Qi, Jiang Xuepeng, Zhao Hongli, Xu Zhisheng, Wei Dong, Smoke-extracting rate model for the tunnel-use system based on the multi-index constraints, Journal of Safe and Environment (01)(2012)191-195

[4] Yi Liang, Li Yanzong, Xu Zhisheng, Experimental study on effect of semi-horizongtal extraction on tunnel fire, Journal of Disaster and Mitigation Engineering (01)(2011) 85-90

[5] O. Vauquelin, M. O, Smoke extraction experiments in case of fire in a tunnel, FIRE SAFET Y J 37(5)(2002) 525-533

[6] Zhao Hongli, Xu Zhisheng, Li Hong, Jiang Xuepeng, Li Dong, Impact of slope on smoke temperature distribution in tunnel fires, Journal of Central South University(Science and Technoloty) (10)(2013)4257-4263

[7] Yi Liang, Yang Yang, Xu Zhisheng, Wu Dexing, Li Weiping, Maximum temoerature of smoke near vault in road tunnel fires with longitudinal ventilation, Journal of combustion science and technology 17(2)(2011) 109-114

[8] L.H. Hua, L.F. Chen, L. Wu, Y.F. Li, J.Y. Zhang, N. Meng, An experimental investigation and correlation on buoyant gas temperat ure below ceiling in a slopping tunnel fire, Appl. Therm. Eng (51)(2013).

[9] L. Yi, Q. Xu, Z. Xu, D. Wu, An experimental study on critical velocity in sloping tunnel with longitudinal ventilation under fire, TUNN UNDERGR SP TECH 43(2014) 198-203

[10] G.H. Ko, S.R. Kim, H.S. Ryou, An experimental study on the effect of slope on the critical velocity in tunnel fires, J FIRE SCI 28(1)(2010) 27-47

[11] A. G, T. Wu, Smoke control in sloping tunnels, FIRE SAFETY J 27(4)(1996) 335-341

[12] Zhang Na, Dai Guoping, Guo Guangling, Ma Shijie, CFD simulation of smoke control in sloping tunnels, Highway (5)(2005) 180-182.

[13] R. Ballesteros-Tajadura, C. Santolaria-Morros, E. BlancoMarigorta, Influence of the slope in the ventilation semi-transversal system of an urban tunnel, Tunnelling and Underground Space Technology incorporating Trenchless Technology Research 21(1)(2006) 21-28.

[14] P. Lin, S.M. Lo, T. Li, Numerical study on the impact of gradient on semi-transverse smoke control system in tunnel, TUNN UNDERGR SP TECH 44(2014)68-79.

[15] L.H. Hu, R. Huo, W. Peng, W.K. Chow, R.X. Yang, On the maximum smoke temperature under the ceiling in tunnel fires, TUNN UNDERGR SP TECH 21(6)(2006)650-655.

[16] L.H. Hu, W. Peng, R. Huo, Critical wind velocity for arresting upwind gas and smoke dispersion induced by near-wall fire in a road tunnel, J HAZARD MATER 150(1)(2008) 68-75.

[17] S.R. Lee, H.S. Ryou, A numerical study on smoke movement in longitudinal ventilation tunnel fires for different aspect ratio, BUILD ENVIRON 41(6)(2006) 719-725.

[18] Technical specification for building smoke control, DJG08-88, 2006, pp

[19] K.B. McGrattan, H.R. Baum, R.G. Rehm, Large Eddy simulations of smoke movement, FIRE SAFETY J 30(2)(1998) 161-178. 